\title{
THE HACKER
}

AND THE STATE 



\section{THE HACKER AND THE STATE}

Cyber Attacks and the New Normal of Geopolitics

Ben Buchanan

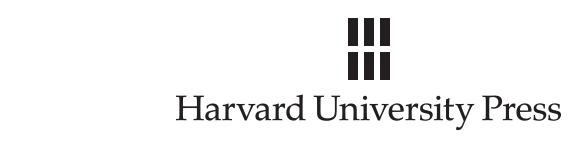

Cambridge, Massachusetts, and London, England 2020 
Copyright (C) 2020 by Ben Buchanan

All rights reserved

Printed in the United States of America

First printing

Jacket image: Aerial photograph of the National Reconnaissance Office by Trevor Paglen, 2013.

Jacket design: Tim Jones

9780674245983 (EPUB)

9780674245990 (MOBI)

9780674246010 (PDF)

The Library of Congress has cataloged the printed edition as follows:

Names: Buchanan, Ben (Writer on cybersecurity), author.

Title: The hacker and the state : cyber attacks and the new normal of geopolitics / Ben Buchanan.

Description: Cambridge, Massachusetts : Harvard University Press, 2020.| Includes bibliographical references and index.

Identifiers: LCCN 2019033274 | ISBN 9780674987555 (cloth)

Subjects: Cyber intelligence (Computer security). | Hacking-Political aspects. | Cyberterrorism. | Cyberspace operations (Military science). |

Cyberspace-Political aspects.

Classification: QA76.9.A25 B823 2020| DDC-dc23

LC record available at https://lccn.loc.gov/2019033274 
For Kelly 
